\title{
Heat Transfer from Two Spheroids in Tandem to a Power Law Fluid by Forced and Mixed Convection Modes
}

\author{
B. Sreenivasulu ${ }^{1}$, B. Ravali Sree ${ }^{2}$, B. Srinivas ${ }^{1}$, K.V. Ramesh ${ }^{2 *}$ \\ ${ }^{1}$ Department of Chemical Engineering, Gayatri Vidya Parishad College of Engineering(A), Visakhapatnam 530048, India \\ ${ }^{2}$ Department of Chemical Engineering, Andhra University, Visakhapatnam 530003, India
}

Corresponding Author Email: kvramesh69@yahoo.com

https://doi.org/10.18280/ti-ijes.642-431

Received: 5 January 2020

Accepted: 25 May 2020

\section{Keywords:}

forced convection, heat transfer, mixed convection, Nusselt number, power law, spheroid

\begin{abstract}
A numerical study is carried out on convective heat transfer from an unconfined and stationary tandem of two spheroids to the surrounding flowing power law fluid of constant physical properties. Two modes of convection viz., forced convection and mixed convection are considered for the present study. The surface of both the spheroids is maintained at constant temperature. The focus of the investigation is to obtain the effect of pertinent variables (Reynolds number, Prandtl number, Richardson number, aspect ratio, power law index and space between two spheroids) on the average Nusselt number. Reynolds number is taken as 1, 25, 50 and 100. Prandtl number considered is 1 and 100 . Chosen range is 0.5 to 2.0 for power law index. Spacings taken are $4 \mathrm{a}$ and $8 \mathrm{a}$ (here $2 \mathrm{a}$ is the length of spheroid in direction parallel to flow). The study is also repeated for the case of mixed convection where in Richardson number is taken as $0.5,12,1.5$ and 2.0.
\end{abstract}

\section{INTRODUCTION}

Flow past solid objects is found in numerous operations such as heat exchangers, fluidized reactors, packed columns, cyclones, filters, thickeners, catalytic reactors, pneumatic conveyors etc. Wide applications are found in process industry, food processing, polymer synthesis, mineral processing, drug synthesis, membrane separations, hydraulic transport etc. In addition, many instruments employ this concept in measurement of quantities in viscometers, chromatographs etc. Therefore, one can understand that there are plenty of applications of flow of fluids over immersed objects [1]. The successful handling of design and operation of such systems depends on thorough understanding of the underlying transport phenomena. A good number of works have been reported earlier with cylinders $[2,3]$ and spheres [4-9] as immersed objects. An examination of literature revealed that previous works pertaining to spheroids are focused on transport properties in case of Newtonian fluids [10-13], power law fluids [14-16] and tandem spheroids in Newtonian fluids [17-19] whereas studies on tandem spheroids in power law fluids is scarce [20].

The purpose of the present study is to analyze the mathematical model of the forced convection and mixed convection modes from two hot spheroids arranged at tandem in a power law fluid which was simulated and solved numerically. The present study aims to focus specifically on the influence of the aspect ratio, the power law index, the Reynolds number, Richardson number and the Prandtl number on the average Nusselt number, velocity streamlines and isotherm distributions.

\section{PROBLEM STATEMENT AND MATHEMATICAL FORMULATION}

The diagrammatic representation of the problem under consideration is depicted in Figure 1. A power law fluid is moving past a stationary arrangement in steady state consisting of two identical spheroids in tandem at finite Reynolds number. Normal to the flow direction, the length of the spheroid is $2 b$ and parallel to flow, the length of the spheroid is $2 \mathrm{a}$. For aspect ratio e less than one, the spheroid is oblate and for e greater than one, prolate spheroid results. When e is equal to one, then the spheroid becomes sphere. The fluid obeys power law, and moves with a velocity $\mathrm{U}_{\infty}$ and temperature $T_{\infty}$ in the far field. The temperature of both the spheroids is kept constant at $\mathrm{T}_{\mathrm{w}}$ which is greater than $\mathrm{T}_{\infty}$, distributions for oblate, sphere and prolate respectively.

The assumptions considered in developing the mathematical model are: (i) the gravitational force acts in the vertically downward direction; (ii) the viscous dissipation terms are neglected; (iii) radiation effect is insignificant; (iv) no slip condition for flow; (v) imaginary surfaces are created because it is not possible to simulate unbounded flow situation; (vi) physical properties of the fluid remain unchanged; (vii) at inlet the fluid has uniform velocity with boundary condition $\mathrm{V}_{\mathrm{r}}=0 ; \mathrm{V}_{\mathrm{z}}=1 ; \mathrm{T}=0$. and (viii) the outflow is fully developed with boundary condition $\frac{\partial V_{z}}{\partial z}=$ $\frac{\partial V_{r}}{\partial z}=\frac{\partial T}{\partial z}=0$. By applying these assumptions, the mathematical model comprises of the equations in dimensionless form shown in Table 1. 
Table 1. Equations present in the mathematical model

\begin{tabular}{|c|c|c|}
\hline Description & Equation & Number \\
\hline Equation of continuity & $\nabla . V=0$ & (1) \\
\hline Equation of momentum & $\begin{array}{c}V . \nabla V=-\nabla P+ \\
\frac{1}{R e} \nabla \cdot \tau_{i j}\end{array}$ & (2) \\
\hline Equation of energy & $V \cdot \nabla T=\frac{1}{R e P r} \nabla^{2} \mathrm{~T}$ & (3) \\
\hline Stress tensor & $\tau_{i j}=2 \eta \varepsilon_{i j}$ & (4) \\
\hline Strain rate tensor & $\varepsilon_{\mathrm{ij}}=\frac{1}{2}\left(\frac{\partial V_{i}}{\partial x_{j}}+\frac{\partial V_{j}}{\partial x_{i}}\right)$ & (5) \\
\hline Viscosity & $\eta=\frac{\mathrm{I}}{2}_{2}^{\left(\frac{\mathrm{n}-1}{2}\right)}$ & (6) \\
\hline Characteristic length & $\mathrm{L}=2 \mathrm{~b}$ & (7) \\
\hline Local Nusselt number & $N u_{\theta}=-\frac{\partial T}{\partial \hat{n}}$ & (8) \\
\hline $\begin{array}{c}\text { Average Nusselt } \\
\text { number }\end{array}$ & $\begin{array}{c}N u= \\
\frac{1}{2} \int_{0}^{\pi} N u_{\theta} \sin \theta d \theta\end{array}$ & (9) \\
\hline $\begin{array}{l}\text { At right vertical edge } \\
\text { (plane of symmetry) }\end{array}$ & $\begin{array}{l}\frac{\partial \mathrm{V}_{\mathrm{z}}}{\partial \mathrm{r}}=\frac{\partial \mathrm{T}}{\partial \mathrm{r}}=0, \mathrm{~V}_{\mathrm{r}} \\
=0\end{array}$ & $(10)$ \\
\hline
\end{tabular}

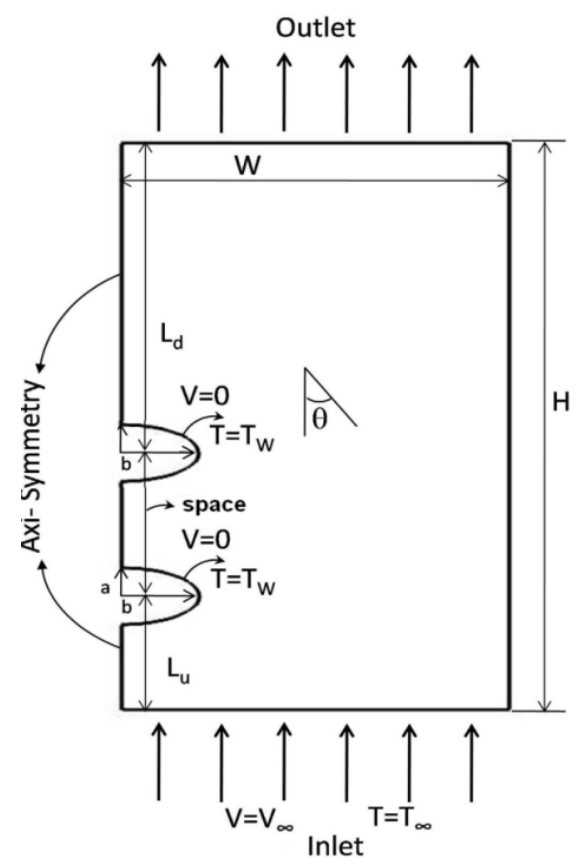

Figure 1. Flow past in a tandem spheroid geometry

\section{NUMERICAL METHODOLOGY}

Eqns. (1) to (10) mathematically describe the system shown in Figure 1. With relevant boundary conditions this problem is solved numerically using COMSOL Multiphysics solver. The region surrounding the spheroid, which is in close proximity to the surface, comprises of steep temperature and velocity gradients. This requires construction of an extremely fine mesh. In the present work, triangular cells were used to mesh the domain. Also steady, axi-symmetric, laminar flow and heat transfer in fluid flow modules are used with PARDISO scheme to solve the set of equations. Relative tolerance for primary convergence criterion is selected as $10^{-6}$ which yields Nusselt number accurate to four significant digits.

Table 2. Parameters used to characterize the domain

\begin{tabular}{ccc}
\hline Parameter & Description & Value \\
\hline $\mathrm{L}_{\mathrm{u}}$ & upstream length & 200 \\
$\mathrm{~L}_{\mathrm{d}}$ & downstream length & 500 \\
$\mathrm{~S}$ & space between spheroids & - \\
$\mathrm{W}$ & width of domain & 60 \\
$\mathrm{H}$ & height of domain & 120 \\
\hline
\end{tabular}

To benchmark the present numerical procedure, simulations had been carried out for validating the present code. The results of validation are shown in Table 3 .

\section{DOMAIN AND GRID INDEPENDENCE}

Initially selection of proper grid is made by using grid refinement approach. The chosen physical domain has been meshed with finite element grid as shown in Figure 2. The grid refinement test data conducted on Reynolds number, Prandtl number, power law index $\mathrm{n}=1$, and aspect ratio $\mathrm{e}=2$. For measuring the accuracy of the solution average Nusselt number is selected as monitoring variable. The parameters that characterize the domain shown in Figure 1 are provided in Table 2. All these parameters are scaled out with sphere diameter. To yield accurate result, the values chosen for these parameters are presented in third column of Table 2. The domain sizes corresponding to the selected case have been used in generating the simulation results in the paper.
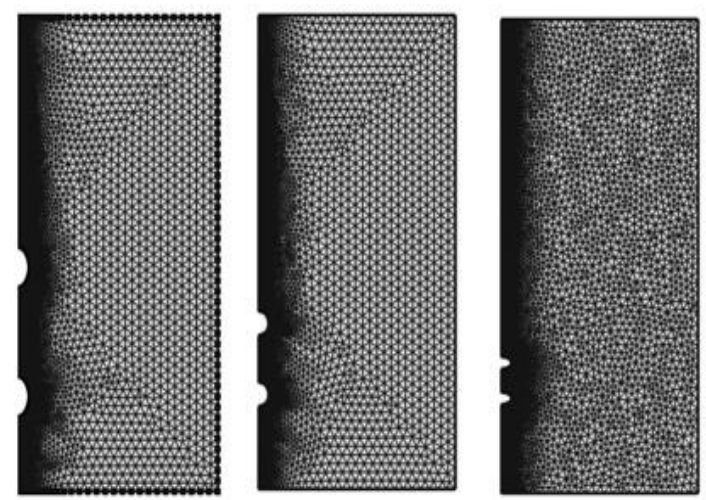

Figure 2. A typical grid distribution with quadrilateral cell

Table 3. Validation of the present work

\begin{tabular}{|c|c|c|c|c|}
\hline Reference & geometry of the object & surrounding fluid & Study (heat transfer) & Avg. Deviation \\
\hline Juncu [2] & two tandem circular cylinders & Newtonian & forced convection & $<2 \%$ \\
\hline Bhattacharya and Singh [4] & sphere & Newtonian & mixed convection & $<2 \%$ \\
\hline Dhole et al. [7] & sphere & power law & steady $2 \mathrm{D}$ axi-symmetric & $<1 \%$ \\
\hline Kotouc et al. [9] & sphere & Newtonian & mixed convection & $<2 \%$ \\
\hline Alassar [11] & oblate spheroid & incompressible fluid & forced convection & $<1 \%$ \\
\hline Kishore and Gu [12] & spheroid & Newtonian & momentum and heat transfer & $<2 \%$ \\
\hline Sreenivasulu et al. [16] & unconfined spheroid & power law & forced convection & $<1 \%$ \\
\hline
\end{tabular}




\section{RESULTS AND DISCUSSION}

The set of equations along with the boundary conditions applied for tandem spheroids were solved to demonstrate the effect of pertinent parameters (Re, Pr, e, n and s) on both flow and temperature using COMSOL Multiphysics solver. The ranges of the parameters selected are for aspect ratio $(0.5$ to 2 ), power law index ( 0.5 to 2.0 ), Reynolds number ( 1 to 100), Prandtl number (1 to 100) and spacing (4a and 8a).

\subsection{Forced convection}

From streamlines and isotherm contour plots (not shown here) the effects of various parameters could be qualitatively described. The shape of the immersed object had strong influence on heat transfer and hence on Nusselt number. By examining Figure 3 and Figure 4, the Nusselt number remained nearly constant with aspect ratio for all values of $n$ and s when Reynolds number is 1 .
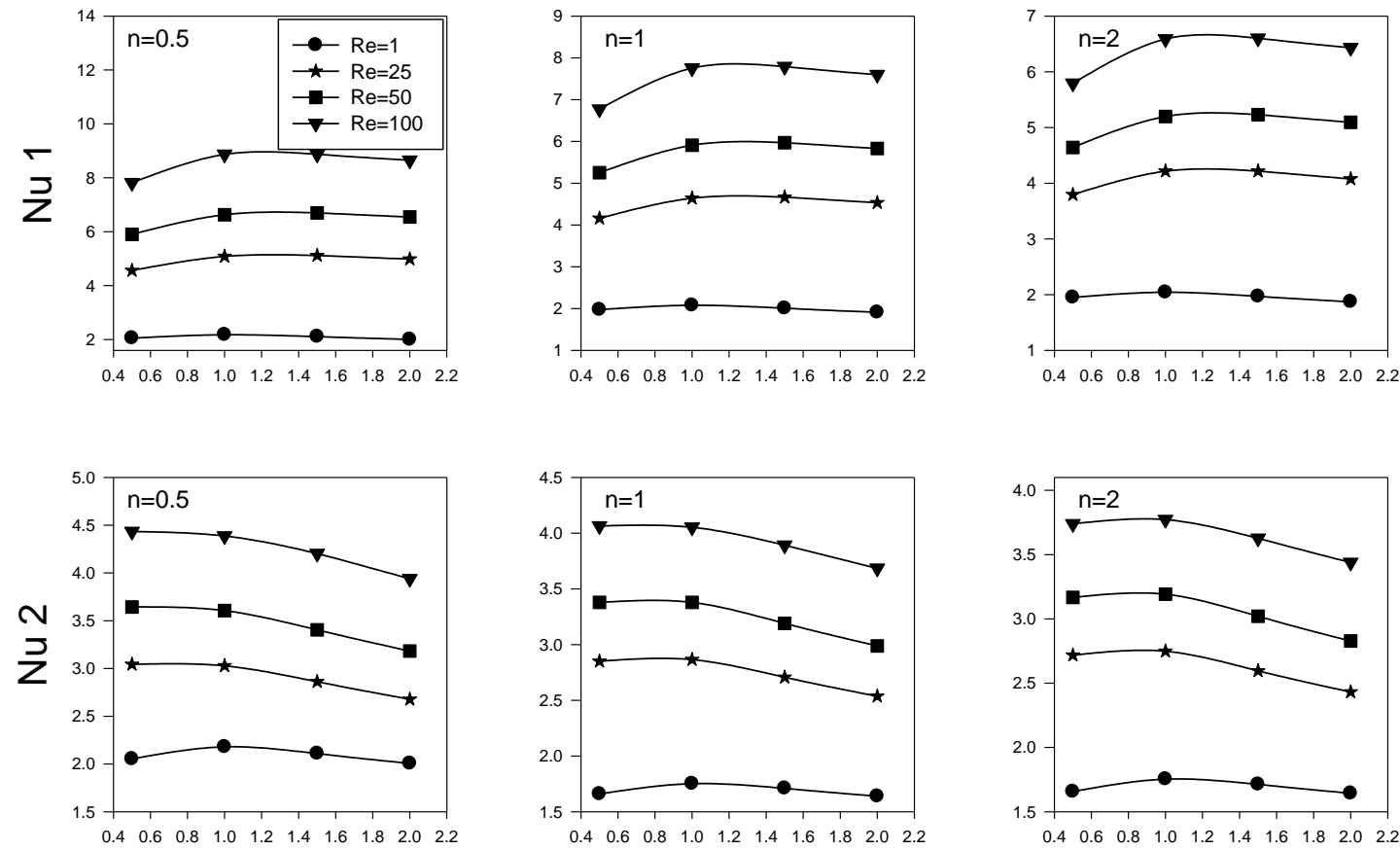

Aspect ratio (e)
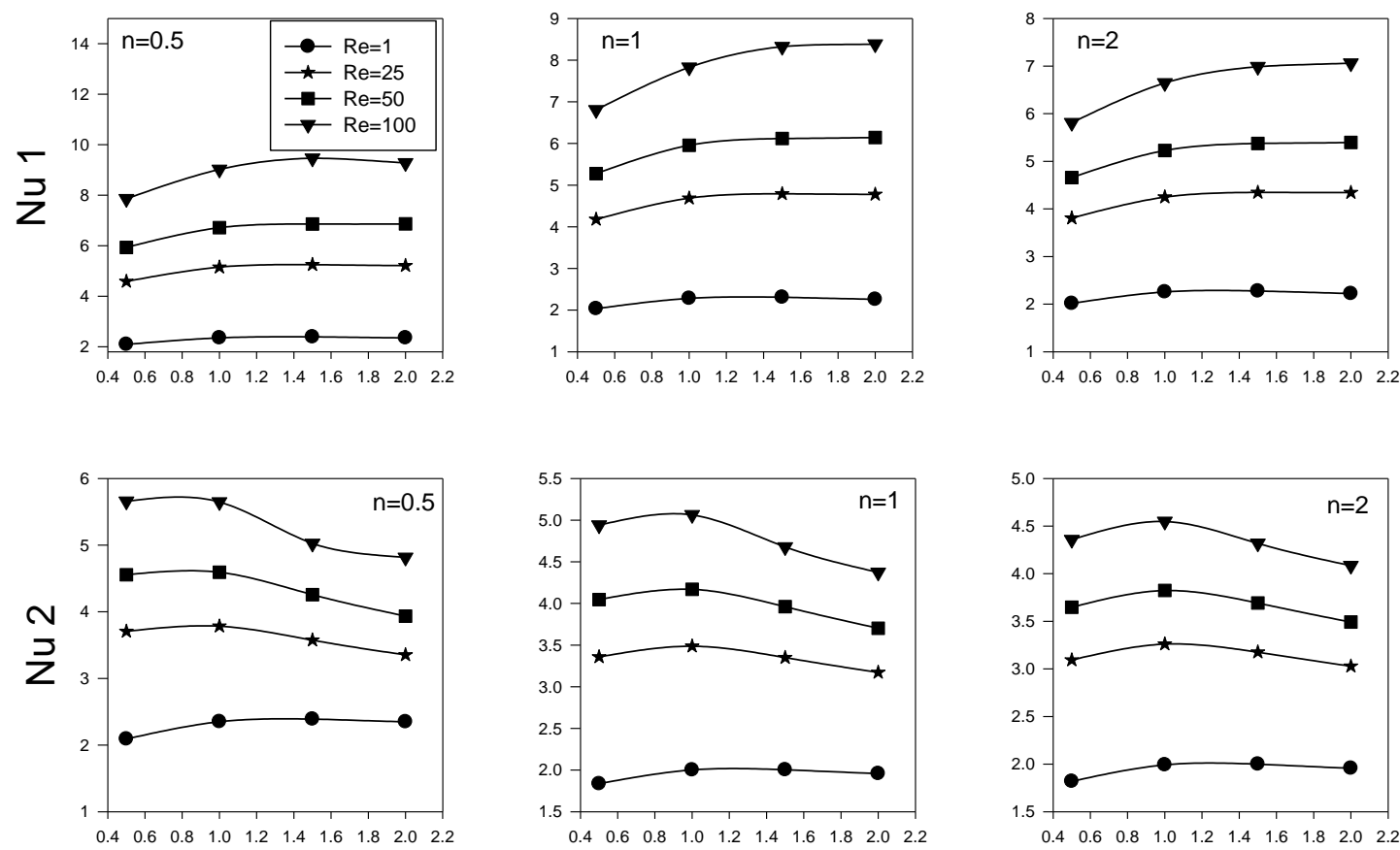

Aspect ratio (e)

Figure 3. Variation of Nusselt number with aspect ratio for different power law indices at $\operatorname{Pr}=1$ ( $\mathrm{s}=4 \mathrm{a}$ for top two rows and $\mathrm{s}=8 \mathrm{a}$ for bottom two rows)

The Nusselt number increased with Reynolds number at any given aspect ratio and power law exponent. When the spacing is $4 \mathrm{a}$, for the first spheroid at any given Re other than 1 , the Nusselt number increased with change of shape from 
oblate to sphere and remained constant for change from sphere to prolate. This is because of nearly unchanged velocity and temperature distributions around the object. But for the second spheroid, the Nusselt number remained constant for change of shape from oblate to sphere and decreased further for change of shape from sphere to prolate, when Prandtl number is 1 owing to increased thickness of boundary layer. At Pr equal to 100, the Nu remained constant with aspect ratio for given Re values of 25 and 50 with variation in shape. This is because both boundary layers are only marginally influenced by the shape of the object at these conditions. But for $\operatorname{Re}$ being 100, the Nusselt number increased with aspect ratio upto 1.5 and remained constant for further change in aspect ratio. This is because of significant rise in turbulent intensity owing to the formation of wakes at both leading and trailing edges of the second spheroid and this intensity is highly dependent on the shape of the spheroid.
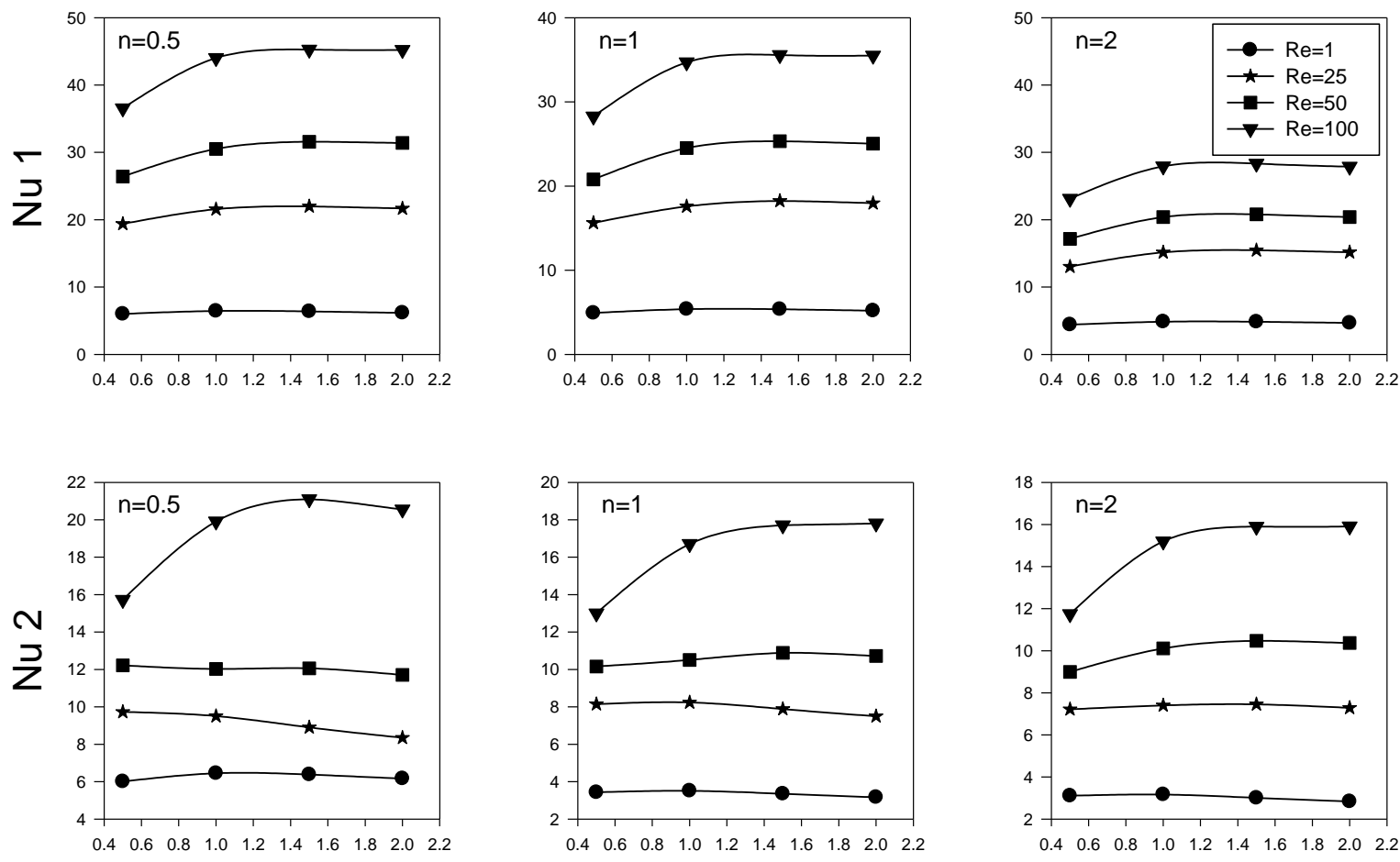

\section{Aspect ratio (e)}
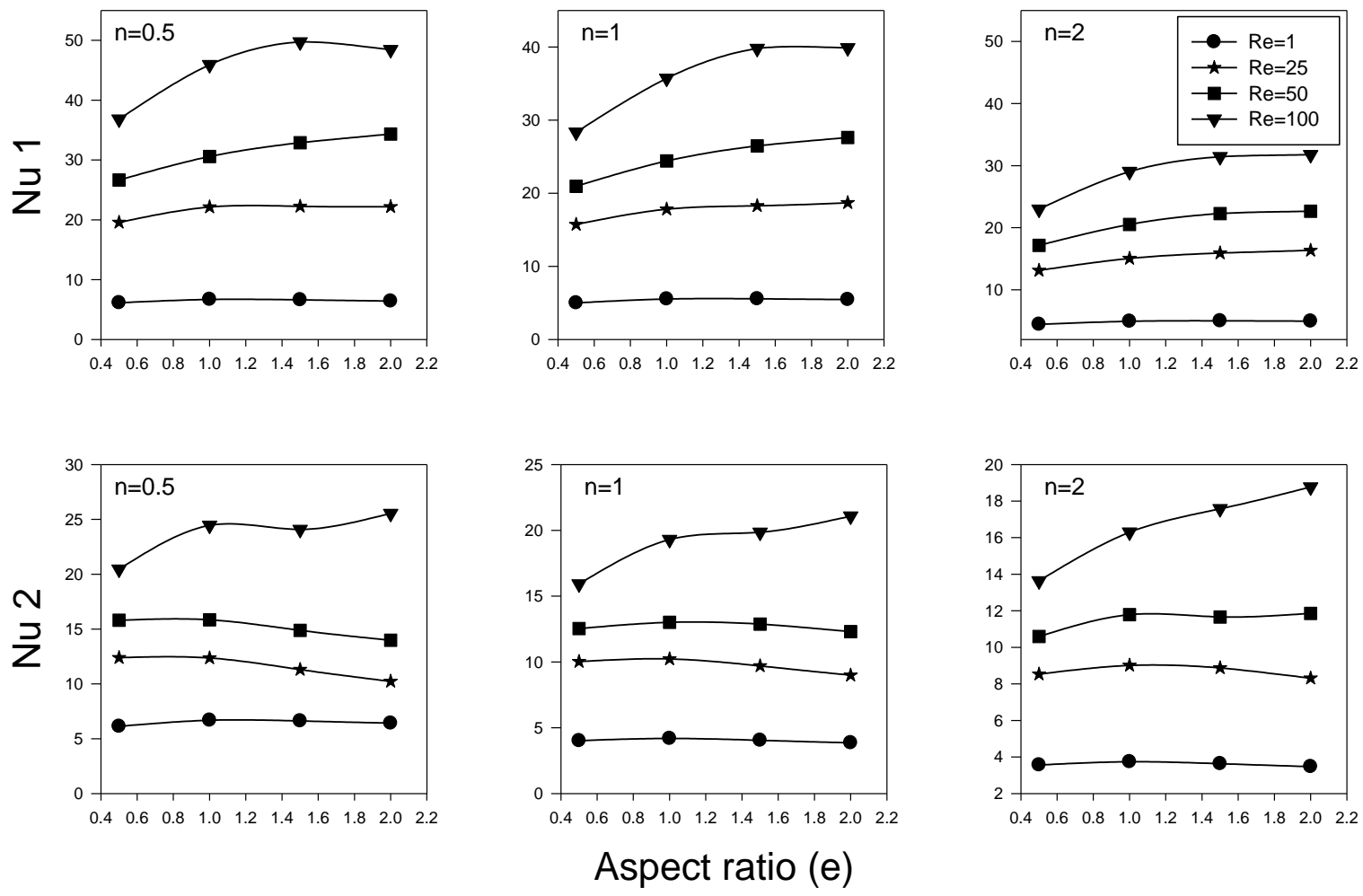

Figure 4. Variation of Nusselt number with aspect ratio for different power law indices at $\operatorname{Pr}=100$. ( $s=4 \mathrm{a}$ for top two rows and $\mathrm{s}=8 \mathrm{a}$ for bottom two rows) 
When spacing is $8 \mathrm{a}$, for the first spheroid, the $\mathrm{Nu}$ got increased with aspect ratio at all $\operatorname{Pr}$ and $\mathrm{n}$. For the case of second spheroid at Pr being 1, there is a slight increase in $\mathrm{Nu}$ with change of shape from oblate to sphere and decreased for change from sphere to prolate. This is for all Reynolds numbers. But for the case of Pr at 100, and Re also at 100, the $\mathrm{Nu}$ number increased with increase in aspect ratio because of significant rise in turbulent activity.

The influence of power law index on the Nusselt number for varied Reynolds number and aspect ratio is shown in Figure 5. For both spheroids, at Re equal to 1, the Nusselt number is not influenced by power law index at any given $\mathrm{e}$ value. At other Re values (25, 50 and 100), pseudoplastics had given out high $\mathrm{Nu}$ values. This is due to less viscosity thus leading to enhanced heat transfer. The power law index has more pronounced effect at higher Pr values for given $\mathrm{Re}$ and $\mathrm{e}$ values. When $\operatorname{Pr}$ is taken as one, the intensity of convective currents is small thus yielding small $\mathrm{Nu}$ values. At large Pr more intense convective currents lead to higher values of Nusselt number. These effects are more prominent in the prolate case compared to the oblate case at all Reynolds numbers. Also, the magnitudes of Nusselt number realized are more for spacing of 8a owing to more turbulence generated by wakes. The value of $\mathrm{Nu}$ decreased with $\mathrm{n}$ and increased with $\mathrm{Re}, \mathrm{Pr}$, aspect ratio and spacing.
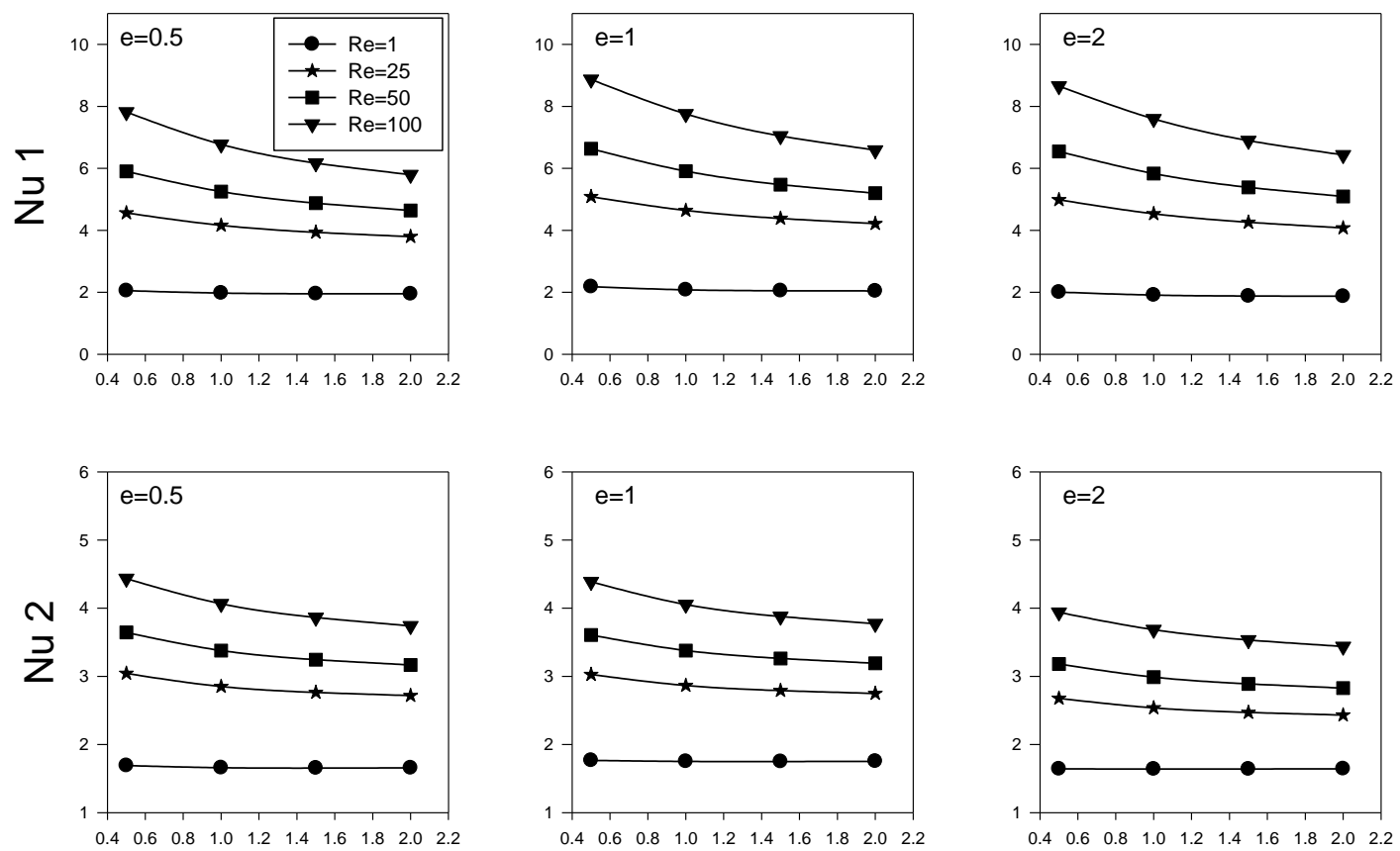

Power law index (n)
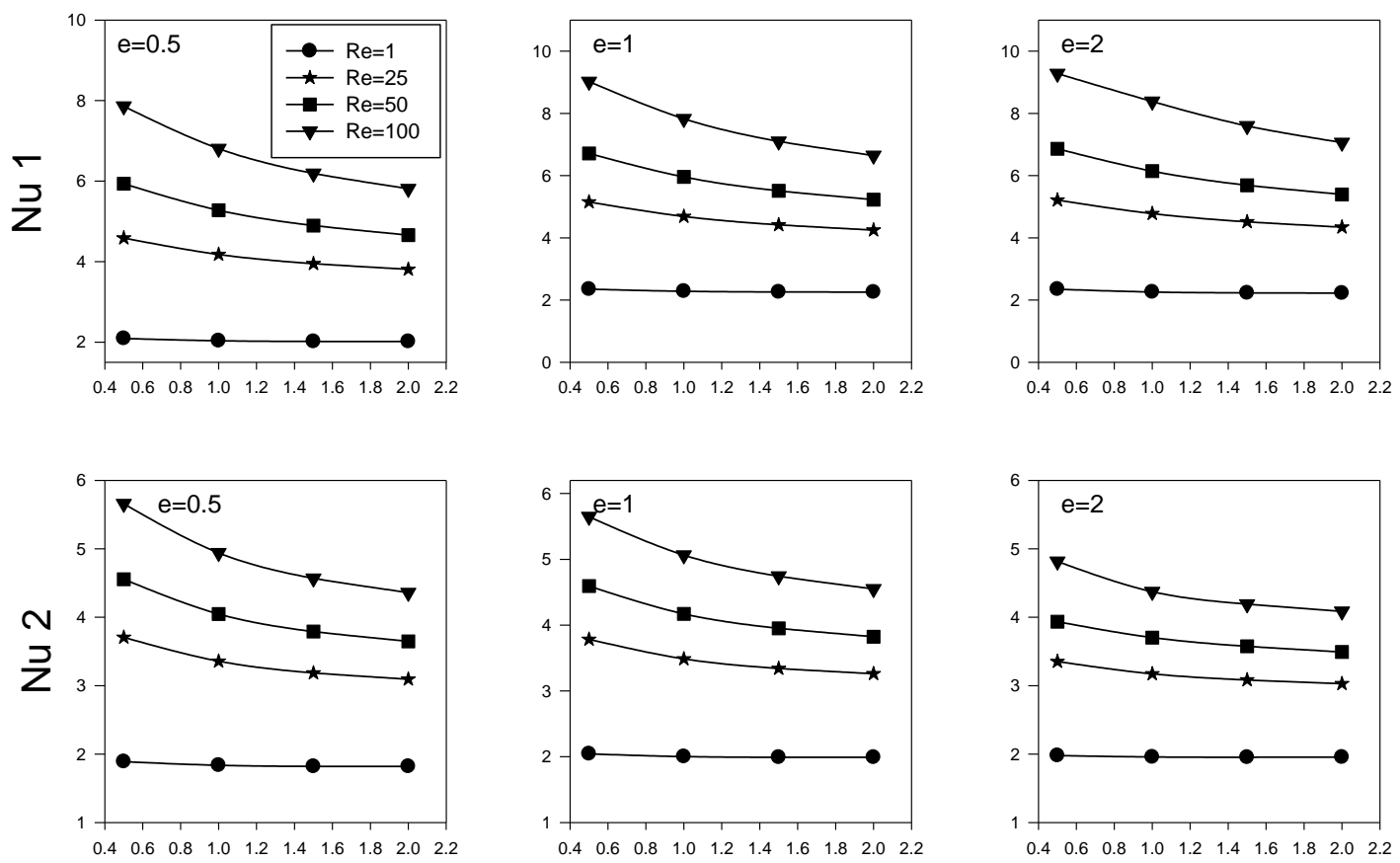

Power law index $(n)$

Figure 5. Variation of Nusselt number with power law index for different aspect ratios at $\operatorname{Pr}=1$. ( $s=4 \mathrm{a}$ for top two rows and $\mathrm{s}=8 \mathrm{a}$ for bottom two rows) 
The influence of Prandtl and Reynolds number on the Nusselt number for different power law indices, aspect ratios and spacings can be seen from Figures 3 to 5. A close inspection of all the plots revealed that the non-Newtonian characteristics attain significance at higher Prandtl and Reynolds numbers. Once the wake formation begins, enhanced heat transfer coefficients could be realized at large Prandtl numbers. At lower Prandtl and Reynolds numbers irrespective of the power law index, the shape of the body as represented by e has marginal effect on Nusselt number. The Nusselt number increased with Reynolds number and this observation is consistent for all cases considered so far in the forced convection study.

\subsection{Mixed convection}

In mixed convection, in addition to the parameters selected for previous case, Richardson number ( $\mathrm{Ri}$ ) is also chosen within the range of 0.5 to 2.0. The effect of aspect ratio on the Nusselt number experienced by the spheroids for different Richardson numbers and power law indices at various Reynolds and Prandtl numbers is presented in Figure 6.
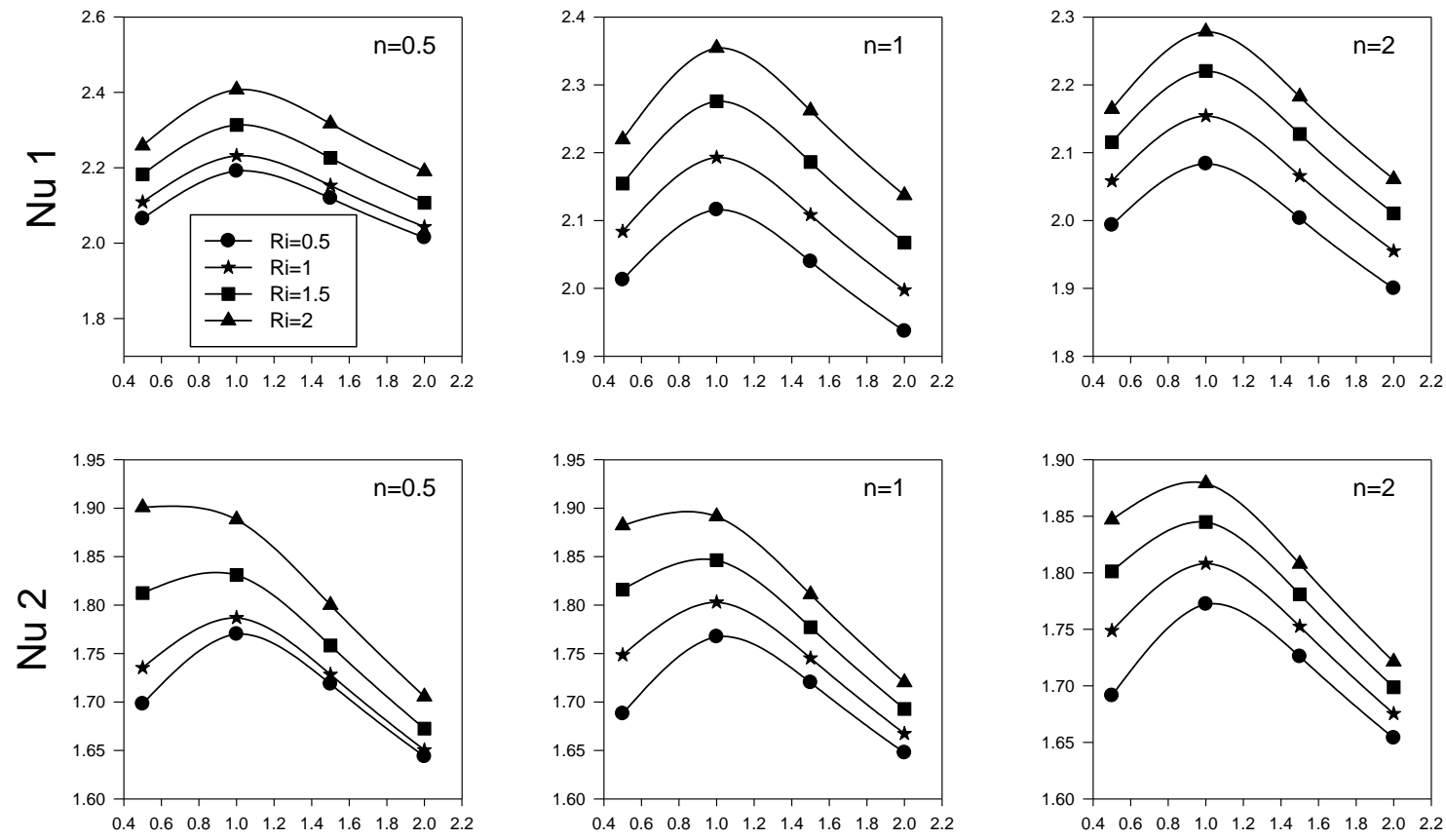

Aspect ratio (e)
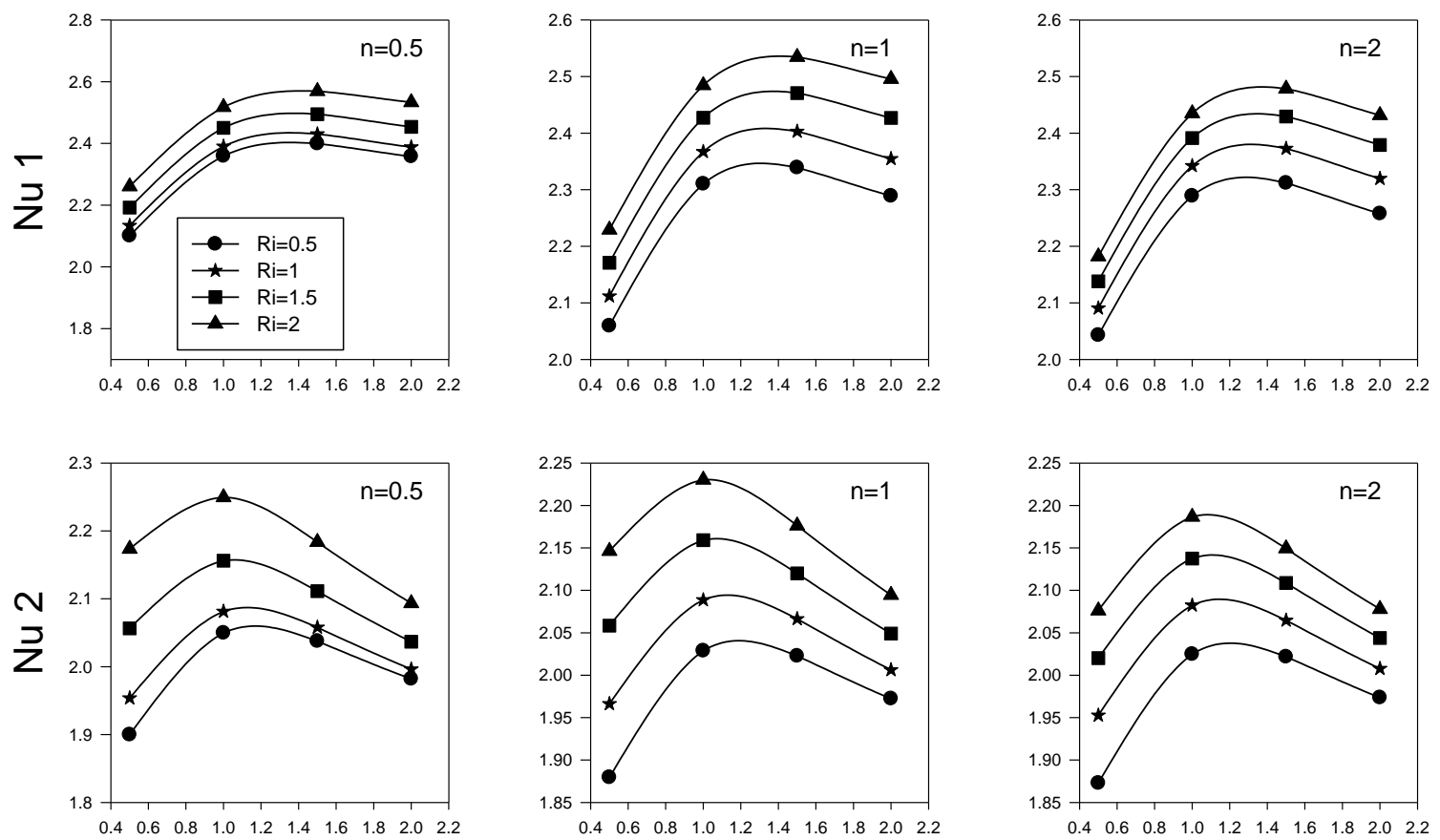

Aspect ratio (e)

Figure 6. Variation of Nusselt number with aspect ratio for different power law index at $\operatorname{Re}=1, \operatorname{Pr}=1$ ( $\mathrm{s}=4 \mathrm{a}$ for top two rows and $\mathrm{s}=8 \mathrm{a}$ for bottom two rows) 
For a given Re, Nusselt number has maximum value for sphere at low Reynolds number and Prandtl number for the spacing 4a for both spheroid and also for second spheroid when spacing is $8 \mathrm{a}$. But for the first spheroid with 8a spacing, highest $\mathrm{Nu}$ value was realized at aspect ratio of 1.5 . This is because, highest turbulent activity could be realized for this geometry at given conditions. The Nusselt number value increased with Richardson number at any given circumstances. It can be observed that maximum Nusselt number can be attained for sphere at low Re and Pr. But at higher Reynolds number and Prandtl number the Nusselt number value is maximum for prolate spheroids at any given power law index.
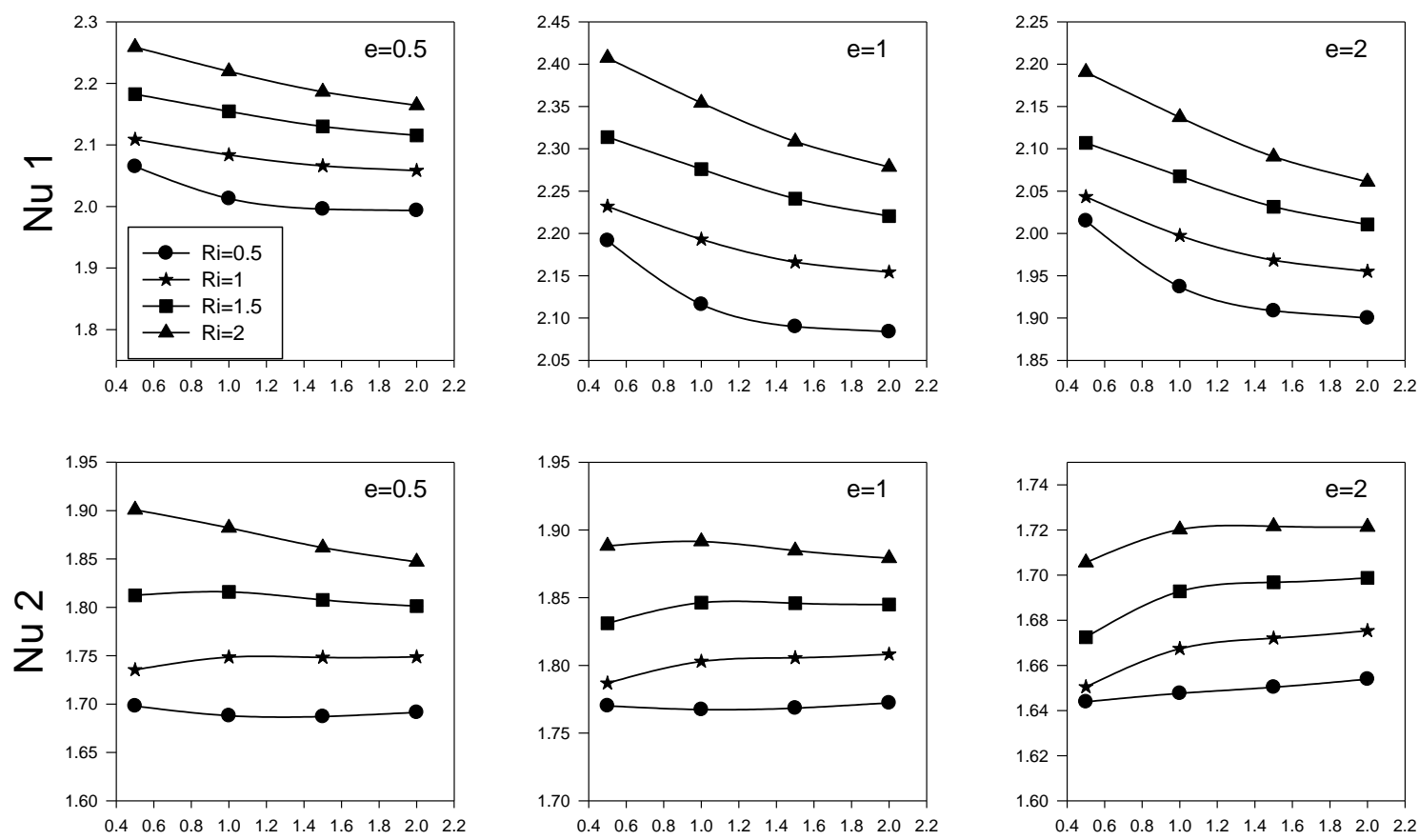

Power law index $(\mathrm{n})$
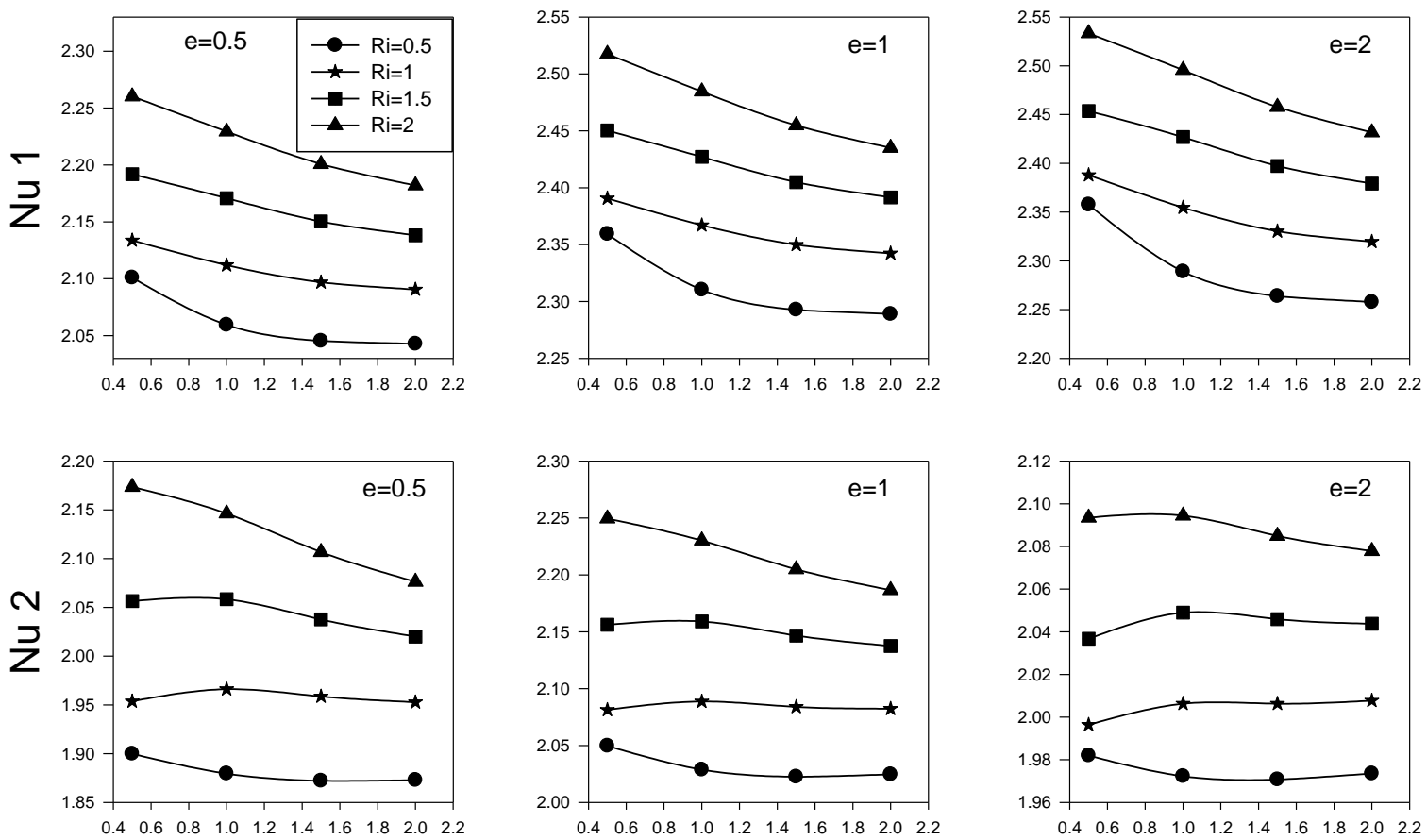

Power law index (n)

Figure 7. Variation of Nusselt number with power law index for different aspect ratio at $\operatorname{Re}=1, \operatorname{Pr}=1$ ( $\mathrm{s}=4 \mathrm{a}$ for top two rows and $\mathrm{s}=8 \mathrm{a}$ for bottom two rows)

The effect of power law index, $n$, on the Nusselt number for varying Richardson number and aspect ratio is shown in Figure 7. It is observed from the graphs that the Nusselt number value decreased with power law index. This means for shear thinning fluids Nusselt number is maximum nearly for all the cases considered. This is because of more turbulent 
activity generated in shear thinning fluids leading to decreased thickness in boundary layers. The effect of Richardson number on the Nusselt number for different power law indices and aspect ratios is shown in Figure 8 . The graph is plotted between Nusselt number for both spheroids versus Richardson number for different aspect ratios. The plots indicate that at small values of $\mathrm{Ri}$ it is the recirculation which is significant and at larger values of $\mathrm{Ri}$ the increased temperature difference between the spheroid and the fluid enhances the heat transfer. As for as the mixed convection is concerned, the trends are same for all spaces considered i.e., 4a, 6a and 8a.
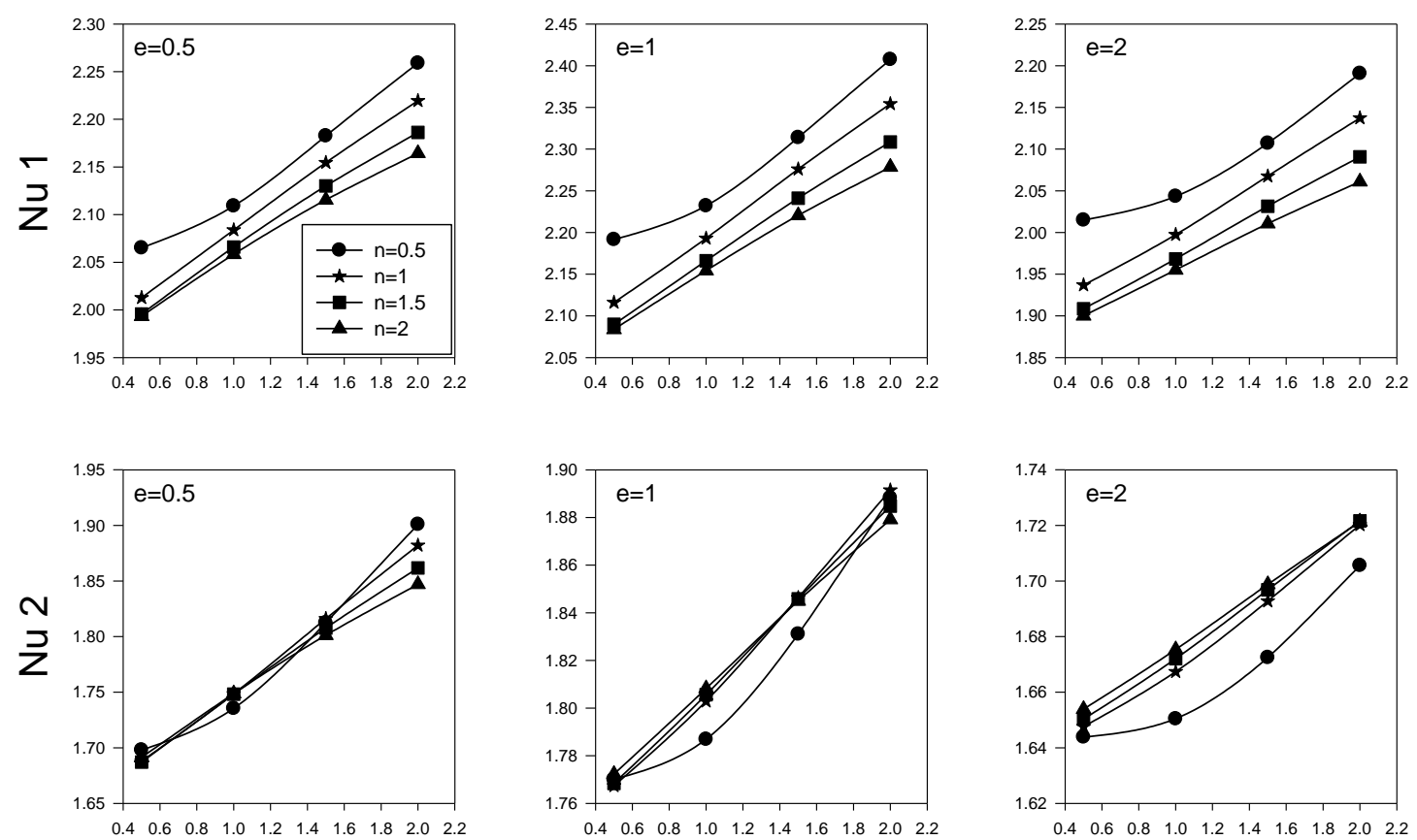

Richardson number (Ri)
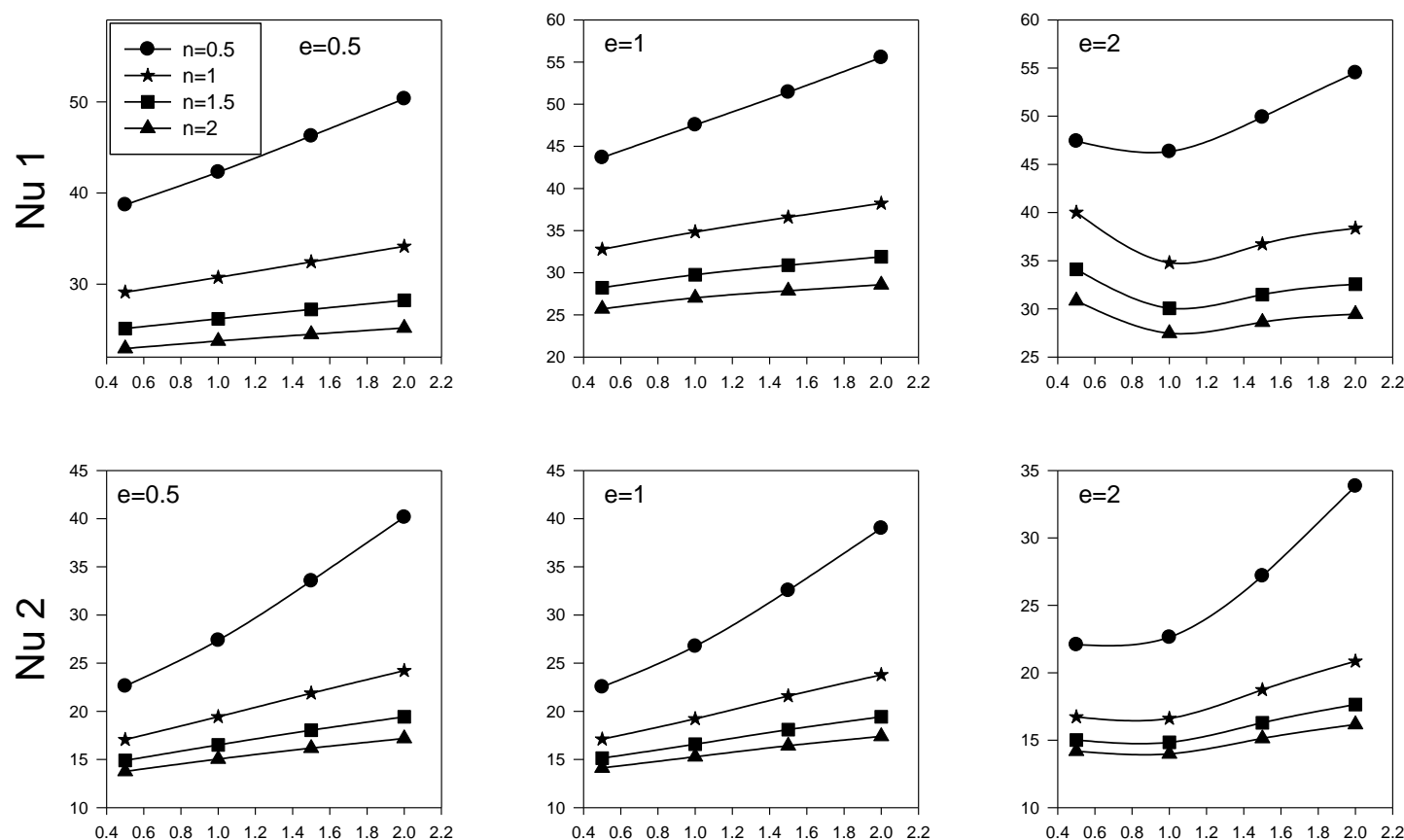

\section{Richardson number (Ri)}

Figure 8. Variation of Nusselt number with Richardson number for different aspect ratios ( $\mathrm{s}=4 \mathrm{a} ; \operatorname{Pr}=1, \operatorname{Re}=1$ for top two rows and $\mathrm{s}=8 \mathrm{a}, \operatorname{Pr}=100, \operatorname{Re}=100$ for bottom two rows)

\section{CONCLUSIONS}

A numerical computation on heat transfer from two tandem spheroids to the surrounded flowing power law fluid had been investigated to know the influence of the Reynolds number, Prandtl number, power law index, aspect ratio and spacing between the spheroids on the average or mean Nusselt number. Two modes of convection viz., forced and mixed were studied in the present investigation. The results of the numerical analysis were summarized here. Overall, it 
can be concluded that for both modes, Nusselt number increased with Reynolds number, Prandtl number and aspect ratio. Nusselt number decreased with power law index. $\mathrm{Nu}$ values obtained for prolate spheroids are higher than oblate spheroids. Pseudoplastic fluids yielded higher $\mathrm{Nu}$ values compared to dilatants fluids. In case of mixed convection Nusselt number increased with Richardson number.

\section{REFERENCES}

[1] Buonomo, B., di Pasqua, A., Monca, O., Nardini, S. (2019). Numerical study on thermal and fluid dynamic behavior of compact heat exchanger partially filled with metal foam. TECNICA ITALIANA-Italian Journal of Engineering Science, 63(2-4): 336-342. https://doi.org/10.18280/ti-ijes.632-432

[2] Juncu, G. (2007). A numerical study of momentum and forced convection heat transfer around two tandem circular cylinders at low Reynolds numbers. Part II: Forced convection heat transfer. International Journal of Heat and Mass Transfer, 50(19-20): 3799-3808. https://doi.org/10.1016/j.ijheatmasstransfer.2007.02.020

[3] Huang, Z., Xi, G., Zhang, W., Wen, S. (2013). Mixed convection heat transfer from confined tandem square cylinders in a horizontal channel. International Journal of Heat and Mass Transfer, 66: 625-631. https://doi.org/10.1016/j.ijheatmasstransfer.2013.07.075

[4] Bhattacharyya, S., Singh, A. (2008). Mixed convection from an isolated spherical particle. International Journal of Heat and Mass Transfer, 51(5-6): 1034-1048. https://doi.org/10.1016/j.ijheatmasstransfer.2007.05.033

[5] Chen, T.S., Mucoglu, A. (1977). Analysis of mixed forced and free convection about a sphere. International Journal of Heat and Mass Transfer, 20(8): 867-875. https://doi.org/10.1016/0017-9310(77)90116-8

[6] Meissner, D.L., Jeng, D.R., De Witt, K.J. (1994). Mixed convection to power-law fluids from two-dimensional or axisymmetric bodies. International Journal of Heat and Mass Transfer, 37(10): 1475-1484. https://doi.org/10.1016/0017-9310(94)90149-X

[7] Dhole, S.D., Chhabra, R.P., Eswaran, V. (2006). Forced convection heat transfer from a sphere to nonNewtonian power law fluids. AIChE Journal, 52(11): 3658-3667. https://doi.org/10.1002/aic.10983

[8] Yamanaka, A., Yuki, T., Mitsuishi, N. (1976). Combined forced and natural convective heat transfer from spheres at small Reynolds number. Journal of Chemical Engineering of Japan, 9(6): 445-449. https://doi.org/10.1252/jcej.9.445

[9] Kotouc, M., Bouchet, G., Dusek, J. (2008). Loss of axisymmetry in the mixed convection, assisting flow past a heated sphere. International Journal of Heat and Mass Transfer, 51(11-12): 2686-2700. https://doi.org/10.1016/j.ijheatmasstransfer.2007.10.005

[10] Masliyah, J.H., Epstein, N. (1972). Numerical solution of heat and mass transfer from spheroids in steady axisymmetric flow. Prog. Heat Mass Transf., 6: 613632. https://doi.org/10.1016/B978-0-08-0170350.50036-7

[11] Alassar, R.S. (2005). Forced convection past an oblate spheroid at low to moderate Reynolds numbers. J. Heat Transf., 127(9): https://doi.org/10.1115/1.1999654

[12] Kishore, N., Gu, S. (2011). Momentum and heat transfer phenomena of spheroid particles at moderate Reynolds and Prandtl numbers. International Journal of Heat and Mass Transfer, 54(11-12): 2595-2601. https://doi.org/10.1016/j.ijheatmasstransfer.2011.02.001

[13] Gupta, A.K., Sasmal, C., Sairamu, M., Chhabra, R.P. (2014). Laminar and steady free convection in powerlaw fluids from a heated spheroidal particle: A numerical study. International Journal of Heat and Mass Transfer, 75: 592-609. https://doi.org/10.1016/j.ijheatmasstransfer.2014.04.008

[14] Reddy, C.R., Kishore, N. (2014). Momentum and heat transfer phenomena of confined spheroid particles in power-law liquids. Ind. Eng. Chem. Res., 53(2): 989998. https://doi.org/10.1021/ie4032428

[15] Srinivas, B., Ramesh, K.V. (2014). Numerical analysis of heat transfer from a spheroidal shaped body to a power law fluid at finite Reynolds number. CFd Lett., 6 : $1-14$.

[16] Sreenivasulu, B., Srinivas, B., Ramesh, K.V. (2014). Forced convection heat transfer from a spheroid to a power law fluid. International Journal of Heat and Mass Transfer, 70: 71-80. https://doi.org/10.1016/j.ijheatmasstransfer.2013.10.065

[17] Sreenivasulu, B., Srinivas, B. (2015). Mixed convection heat transfer from a spheroid to a Newtonian fluid. Int. J. Therm. Sci., 87: 1-18. https://doi.org/10.1016/j.ijthermalsci.2014.08.002

[18] Kishore, N. (2012). Flow and drag phenomena of tandem spheroid particles at finite Reynolds numbers. Ind. Eng. Chem. Res., 51(7): 3186-3196. https://doi.org/10.1021/ie202814w

[19] Kishore, N. (2012). Numerical investigation of interaction between spheroid particles in tandem arrangement at moderate Reynolds numbers. Ind. Eng. Chem. Res., 51(30): 10265-10273. https://doi.org/10.1021/ie3012424

[20] Rathore, A.S., Chaitanya, P., Kishore, N. (2013). Drag of tandem spheroids in power-law fluids at moderate Reynolds numbers. Ind. Eng. Chem. Res., 52(33): 11773-11778. https://doi.org/10.1021/ie4014875

\section{NOMENCLATURE}

a

b

$\mathrm{Gr}$ $\mathrm{h}$

k

$\mathrm{L}$

$\mathrm{Lu}$

Ld

$\hat{n}$

$\mathrm{Nu}$

$\mathrm{Pr}$

$\mathrm{P}$

$\mathrm{Re}$

$\mathrm{Ri}$

$\mathrm{T}$ half length of the axis parallel to flow, $m$ half length of the axis perpendicular to flow, $\mathrm{m}$ specific heat of the fluid, $\mathrm{J} \mathrm{kg}^{-1} \mathrm{~K}^{-1}$

Aspect ratio, b/a Grashof number, $g \beta\left(T_{w}-T_{\infty}\right) L^{3}\left(\frac{\rho_{\infty}}{\eta}\right)^{2}$ heat transfer coefficient, $\mathrm{W} \mathrm{m}^{-2} \mathrm{~K}^{-1}$ thermal conductivity of the fluid, $\mathrm{W} \mathrm{m}^{-1} \mathrm{~K}^{-1}$ characteristic length equal to $2 \mathrm{~b}, \mathrm{~m}$ upstream length, $\mathrm{m}$ downstream length, $m$ unit outward normal to the spheroid surface Nusselt number, $\mathrm{hL} / \mathrm{k}$

Prandtl number, $\mathrm{c}_{\mathrm{p}} \eta / \mathrm{k}$ pressure, $\mathrm{Pa}$ Reynolds number, $\mathrm{LU}_{\infty} \rho / \eta$ Richardson number, $\mathrm{Gr} / \mathrm{Re}^{2}$ space between spheroids, $\mathrm{m}$ fluid temperature (dimensionless) $\left(=\frac{T^{\prime}-T_{\infty}}{T_{w}-T_{\infty}}\right)$ 
$\mathrm{T}_{\mathrm{w}} \quad$ temperature on the surface of the spheroid, $\mathrm{K}$

$T_{\infty} \quad$ fluid temperature in the free stream, $\mathrm{K}$

$U_{\infty} \quad$ far away free stream velocity, $\mathrm{m} \mathrm{s}^{-1}$

$\mathrm{v}_{\mathrm{r}} \quad \mathrm{r}$-component of the velocity, $\mathrm{m} \mathrm{s}^{-1}$

$\mathrm{v}_{\mathrm{z}} \quad$ z-component of the velocity, $\mathrm{m} \mathrm{s}^{-1}$

$\mathrm{W} \quad$ width of the geometry, $\mathrm{m}$

$\mathrm{x} \quad$ stream wise coordinate, $\mathrm{m}$

$\mathrm{y}$ transverse coordinate, $\mathrm{m}$

\section{Greek symbols}

$\varepsilon \quad$ rate of strain tensor, $\mathrm{s}^{-1}$

$\eta \quad$ viscosity of fluid, Pa.s $\theta \quad$ polar angle

$\rho$ density of fluid, $\mathrm{kg} \mathrm{m}^{-3}$

$\rho_{\infty}$ density of fluid at the reference temperature $T_{\infty}, \mathrm{kg} \mathrm{m}^{-3}$

$\tau$ extra stress tensor, $\mathrm{Pa}$

$\beta$ Coefficient of volumetric expansion, $\mathrm{K}^{-1}$

\section{Subscripts}

$\mathrm{i}, \mathrm{j} \quad$ dummy argument

$\mathrm{r}, \mathrm{z} \quad$ cylindrical coordinates

w wall condition 